\title{
O ENSINO DE FILOSOFIA AINDA É RELEVANTE?
}

\section{Ronie Alexsandro Teles da Silveira*}

RESUMO: Há duas maneiras principais pelas quais os filósofos justificaram a importância de sua atividade. A primeira foi entender a Filosofia como responsável pela legitimação de outras formas de conhecimento. A segunda foi entendê-la como a parte mais importante do processo de educação do homem. Entretanto, os valores vigentes na cultura contemporânea privaram essas justificativas do seu sentido e apresentam novos desafios para a relevância da Filosofia.

Palavras-chave: Filosofia Contemporânea; Ensino de Filosofia; Emancipação; Democracia; Relevância

Resumen: Hay dos formas principales en que los filósofos han explicado la importancia de su actividad. El primero era entender la Filosofía como esponsable de la legitimidad de otras formas de conocimiento. El segundo fue para entenderlo como la parte más importante del proceso de educar al hombre. Sin embargo, los valores que prevalecen en la cultura contemporánea han privado estas justificaciones de su sentido e apresentan retos nuevos a la relevancia de la Filosofía.

Palabras claves: Filosofía contemporánea; Enseñanza de la filosofía; Emancipación; Democracia; Relevancia

\section{Introdução}

Nós, os filósofos, não somos conhecidos pela modéstia. Em geral, acreditamos que não existe nada mais importante que o estudo da Filosofia. Quando eu era jovem e me decidi por fazer vestibular para esse curso, o fiz pensando que estava escolhendo uma atividade que era central para a compreensão dos maiores problemas da humanidade. A Filosofia constituía para mim o estudo das questóes que eram realmente importantes e sem o qual nenhuma solução autêntica poderia ser encontrada. Assim, ao me dedicar a ela, eu

\footnotetext{
Universidade Federal da Integral Internacional da Lusofonia Afro-brasileira. E-mail: roniesilveira@yahoo.com.br 
estava me colocando na posição de um investigador do centro do universo ou adotando o comportamento de um estudioso de algo que possui o máximo valor.

Ao tomar essa decisão, eu estava descartando de minhas opções de estudo todas aquelas áreas que não se ocupavam com esse suposto centro das preocupações essenciais da humanidade. Nessa minha crença juvenil está incluída uma valorização extrema da Filosofia e uma consequente desvalorização de tudo aquilo que eu entendia ser periférico: a religião, as demais ciências humanas, as ciências naturais, a arte, o senso comum $e$, por que não dizer, as várias modalidades de trabalho manual. Eu estava separando o centro da periferia, o importante do secundário. E, para mim, o trabalho filosófico sempre ocupava o primeiro lugar entre todas as atividades humanas.

Sendo pessoalmente o protagonista de tal tipo de investigação, é natural que eu terminasse por me julgar tão importante e central quanto o meu próprio objeto de estudo. Acredito que esse é um tipo de crença implícita que a maioria dos filósofos desenvolve ao entrar em contato com o estudo da Filosofia. Assim, a nossa falta de modéstia é praticamente uma consequência psicológica que nos acomete em alguma fase dos estudos filosóficos. Parece que em algum momento, todos nós acreditamos que o que estamos fazendo é decisivo para a humanidade.

Entretanto, essa minha crença juvenil sobre a Filosofia também pode ser explicada como uma manifestação natural de autoestima que toda profissão envolve. Qualquer profissional representa de maneira positiva o trabalho que realiza, sempre procurando destacar suas virtudes e minimizar qualquer aspecto negativo que ele pareça possuir. Como amantes de suas respectivas profissões $-e$ como amantes em geral - todos tendem a diminuir os eventuais defeitos e ampliar as respectivas virtudes. Então, certamente não posso usar minha autoestima natural de filósofo como evidência da importância da Filosofia e do seu ensino nos dias atuais, porque essa é uma atitude que todos têm com relação a suas próprias profissões. Isso terminaria sendo apenas a manifestação tautológica da minha 
própria escolha profissional e de sua consequente falta de modéstia. Assim, se torna necessária alguma outra forma de justificativa.

Parecem existir duas maneiras principais pelas quais os filósofos justificaram, no passado, a importância da atividade a que se dedicam. A primeira foi entender a Filosofia como sendo responsável pela legitimação de outras formas de conhecimento. A segunda foi entendê-la como a parte mais importante do processo de formação do homem. Uma afirmava a centralidade da Filosofia com relação ao sistema geral do conhecimento e a outra dizia o mesmo com respeito ao processo de educação. Abaixo, tento esclarecer o significado de cada uma delas.

\section{O centro metafísico do conhecimento}

A atitude predominante na primeira pode ser identificada com o dispositivo metafísico aristotélico: um saber que implica o conhecimento das últimas causas de todas as coisas e, portanto, leva à posse da chave de todos os problemas epistemológicos. Aristóteles $(1990 ; 2001)$ afirma que o conhecimento consiste na indicação das causas de um fenômeno. Sendo assim, a ciência da causa de todas as causas é o centro a partir do qual se irradia a força explicativa para todas as outras formas de conhecimento.

A Metafísica consiste em uma forma de conhecimento especial, porque é relativa àquilo que Aristóteles julga ser o mais elevado dos objetos de conhecimento: o ser. De posse desse conhecimento seria possível percorrer uma série causal na direção descendente, obtendo a justificação necessária para que toda ciência sobre seres subalternos pudesse se tornar legítima. A Metafísica propicia a ponta inicial e autofundante de um mecanismo que transmite segurança a outras formas de conhecimento inferiores, que se tornam epistemologicamente legítimas justamente em função dessa conexão. Ela estrutura um sistema geral do conhecimento humano a que cada uma das ciências particulares se subordina de 
maneira orgânica, conectando seus princípios básicos com uma cadeia de causalidade que termina no ser.

Assim, cada ciência particular se desenvolve a partir de determinado patamar epistemológico subordinado que é dado pela posição relativa de seus princípios. Esses princípios estão conectados a uma estrutura que lhes dá sustentação e sentido. Se uma ciência se desenvolve sem buscar conectar seus princípios a essa estrutura orgânica, ela pode ser acusada de ilegítima, pois não possui recursos para se posicionar no conjunto do conhecimento $e$ ter seu sentido plenamente reconhecido. Sem tal conexão, pode ser simplesmente que ela não possua princípios legítimos. Sem definir como eles se conectam com o restante do sistema do conhecimento, qualquer ciência carece de fundamentos autênticos e não passa de uma maneira superficial de conhecer.

O pleno conhecimento de um objeto em particular implica, portanto, dois tipos de movimento: um horizontal e um vertical. No horizontal se estabelecem relações causais com outros fenômenos semelhantes dentro de uma mesma hierarquia ontológica e explicativa. No plano vertical, o conhecimento busca conectar-se com um sistema de princípios que the garante um lugar ao sol epistemológico, por meio de sua derivação a partir de outros princípios superiores já estabelecidos. Nesse último caso, ele se enraíza no sistema geral do conhecimento humano e retira daí sua validade.

Não é incomum, ainda hoje, encontrarmos cientistas que exigem que sua ciência possua uma base epistemológica. Isto é entendido como a necessidade de que cada saber ou ramo dele exiba, como uma declaração de autenticidade, a sua derivação a partir de princípios superiores. Sem isso, alguns acreditam que a ciência seria superficial ou carente de fundamentos: ela estaria pairando no ar, desconectada daquela base. A justificação epistemológica implica justamente a conexão entre uma ciência particular e os fundamentos que se encontram em alguma instância filosófica considerada mais profunda ou mais elevada. Isto é, a 
justificativa é obtida pela proximidade com aquele princípio metafísico supremo que irradia a potência epistemológica para a periferia do círculo do conhecimento.

A Filosofia, enquanto ciência dos princípios mais elevados, seria a responsável por propiciar justificação epistemológica a todas as demais formas do conhecimento. Mais uma vez, observamos que é muito natural transpor essa missão central da Filosofia para os seus protagonistas, os filósofos. Por consequência, eles são compreendidos como os responsáveis pelo centro do âmbito do conhecimento, pela derivação de princípios que tornam as ciências particulares autênticas. A autoestima exagerada - e, em alguns casos, até a soberba - é quase uma reação psicológica inevitável diante do papel reservado aos guardiões do processo de legitimação do conhecimento. Caberia a nós - e apenas a nós - julgar se uma forma particular de conhecimento estaria conectada ou não ao restante do sistema. Nenhum outro profissional tem acesso à chave do segredo.

Essa primeira justificativa da importância da Filosofia afirma que ela desempenha um papel central do conhecimento: ela ocuparia o centro de onde irrigaria o restante do conhecimento com fundamentos válidos e com legitimidade. Sem ter sua posição claramente identificada nesse sistema, uma forma de conhecimento seria superficial e ilegítima - um devaneio subjetivo sem raízes epistemológicas. Aos filósofos, por definição, caberia a responsabilidade profissional por esse centro de gravidade que garantiria o estatuto de verdade e o enraizamento, necessário para qualquer forma de conhecimento. Somente ele estaria em condições de avaliar se uma forma particular de saber estaria conectada ou não ao restante do sistema. Somente um filósofo poderia estabelecer essa ligação com as raízes metafísicas do conhecimento, porque essa é sua atividade específica.

\section{O cume da emancipação}


A segunda maneira pela qual os filósofos desenvolveram uma elevada autoestima com relação ao seu trabalho está ligada ao papel da Filosofia no processo de formação do homem. Essa segunda maneira de garantir um papel de destaque para a Filosofia pode ser encontrada na atitude presente no pensamento de Hegel (1983; 1988).

Hegel afirmou que as diferentes formas de conhecimento eram momentos da luta do Espírito para chegar à plena consciência de si mesmo e atingir a liberdade verdadeira. Cada uma delas corresponderia a uma etapa específica do processo de libertação do Espírito. Assim, a História é valorizada como o processo de formação da consciência definitiva do Espírito que implicará na obtenção de sua liberdade (SILVA, 2012). Observe que Hegel afirma a equivalência entre a posse do conhecimento e a obtenção da liberdade, de tal forma que a educação passa a ser também um processo de emancipação e não somente um processo de ampliação cognitiva. Para ele, essa última implicaria também na obtenção de níveis maiores de liberdade.

Transpondo a lógica de formação do Espírito para o plano individual obtemos a seguinte situação: em um primeiro momento, o indivíduo adquire uma forma de conhecimento particular que corresponde a um estágio precário de liberdade. Mas esse conhecimento particular ainda não possui a forma adequada, isto é, ele ainda não fornece liberdade plena e conhecimento de si ao indivíduo. Em função de sua própria particularidade, de ser um conhecimento entre tantos outros, ele possui limitações e necessita ser expandido. Para isso, se requer alguma forma de conhecimento superior e mais abrangente que possa ampliar a liberdade, sem perder o elemento positivo que já foi conquistado. Então, o conhecimento particular inicial precisa ser compreendido por um ponto de vista mais elevado.

O processo de formação de um indivíduo passa por várias etapas formativas que vão se sobrepondo, como círculos cada vez mais amplos, que propiciam níveis de liberdade e de compreensão de si mesmo cada vez maiores. A cada expansão da compreensão e da liberdade se preserva o que foi obtido antes na luta do 
indivíduo contra suas próprias limitações. Essa dupla relação implica, por um lado, em superação dos limites existentes e, por outro, em conservação do aspecto positivo. Essa dupla função, contida no progresso existente entre uma etapa $e$ outra, é uma característica do pensamento de Hegel (1992) e foi traduzida por suprassunção (Aufhebung).

Para tornar o significado do progresso da emancipação mais claro, considere o que ele significa no contexto do ensino superior. Nesse caso, o processo de educação implica a necessidade de que os futuros profissionais se tornem críticos. Ou seja, que eles ampliem sua perspectiva e vejam além do saber instrumental particular que recebem em um curso superior, que sejam cidadãos que compreendam o impacto de suas práticas profissionais na sociedade em que estão inseridos, que vejam além do aspecto imediato do conhecimento particular que receberam inicialmente. Enfim, que suprassumam a sua própria condição de detentores de um conhecimento e de um grau de liberdade particulares e se posicionem em uma esfera superior de saber e de existência.

A crítica é o conhecimento das limitações atuais, a percepção de que se ocupa uma posição relativa em um contexto específico e o impulso para se adotar uma perspectiva mais abrangente. Isto é, a crítica envolve a perspectiva de progresso e de emancipação gradativa na medida em que se reconhecem as limitações de qualquer tipo particular de conhecimento. Assim, o ensino tem de ser crítico: ele tem de remeter sempre para um nível mais amplo de compreensão do conhecimento e do indivíduo.

A Filosofia, para Hegel, seria a responsável pelo maior nível de abrangência possível no processo de formação do Espírito. Não haveria emancipação autêntica sem atividade filosófica. Novamente aqui, mas por motivos muito diversos dos de Aristóteles, a Filosofia ocupa o lugar principal dentre todas as formas de conhecimento. Ela propicia a visão mais ampla que dá acesso à verdade relativa de todos os conhecimentos particulares e os coloca sob a perspectiva correta, ao valorizar o que há de positivo em cada um e indicar suas respectivas limitações, 
ampliando o círculo de significado de cada etapa particular. Ela é a responsável pela realização do patamar mais elevado de liberdade. Em outras palavras, a liberdade ou a emancipação plena do homem só são possíveis por meio da atividade filosófica. Ela é o fim último a que tende todo processo de educação autêntico - ou, como diria a poeta (PRADO, 2007, p. 89), ela é o "cúmice do ápice" da emancipação.

Certamente há outras formas de se justificar a importância da Filosofia e do seu ensino, mas essas duas que apresentei acima me parecem mais significativas não somente do ponto de vista histórico, como do ponto de vista da tipificação de um senso filosófico de dignidade - aquilo que caracteriza o que normalmente os filósofos entendem como sendo o trabalho que devem realizar. Entretanto, ambas as manifestações são formas históricas do passado: a de Aristóteles possui mais de dois mil anos e a de Hegel já está com aproximadamente duzentos anos de idade.

Assim, após essa caracterização simplificada da origem da falta de modéstia e da elevada autoestima dos filósofos sobre si mesmos, há uma questão que inevitavelmente precisa ser respondida: o mundo atual ainda admite essas duas formas históricas de justificação da atividade filosófica? Os valores culturais vigentes ainda propiciam pertinência e centralidade para o ensino de Filosofia nos termos de Aristóteles e Hegel? A Filosofia possui um valor garantido no presente?

Para responder a isso, precisamos partir de alguma avaliação sobre a situação cultural em que vivemos e que nos permita identificar, ao menos de forma sumária, quais são os principais valores vigentes nos dias de hoje. Só então estaremos em condições de compará-los com aquelas crenças, metafísica e emancipatória, acerca do trabalho filosófico.

\section{A horizontalidade dos valores}


Vou utilizar um diagnóstico sobre a situação geral do conhecimento, publicado no final dos anos de 1970 do século XX, que me parece ainda bastante adequado para descrever alguns valores vigentes. Isso é certamente arriscado em função da simplificação extrema a que obriga, mas possui a vantagem de permitir colocar em destaque as limitações daquelas duas formas históricas de se afirmar a centralidade da Filosofia para o conhecimento e para a educação.

Lyotard (2002), autor do diagnóstico a que me referi, afirma que a condição contemporânea do conhecimento é caracterizada pela falência das metanarrativas. Isso significa que o valor de uma forma de conhecimento particular não é mais buscado em uma instância superior. Para ele, não se requer mais a conexão entre um saber específico e um saber mais abrangente para se garantir a legitimidade do primeiro. Nessa situação, o conhecimento se torna legítimo simplesmente porque existe para uma comunidade que o utiliza e o faz avançar de acordo com seus próprios parâmetros.

A justificação de uma forma particular de conhecimento encontra-se no fato mesmo de sua existência e não em uma instância superior de onde ela poderia ser derivada. Suas características básicas não são derivadas de outra esfera, mas obtidas por procedimentos que se busca explicar em termos imanentes ao funcionamento de uma comunidade de cientistas. A obra de Kuhn (1989) é um bom exemplo de como a discussão contemporânea sobre o conhecimento e a ciência vem dando destaque a esses elementos imanentes, presentes no processo prático de elaboração do conhecimento. Os aspectos sociológicos são componentes explicativos que não remetem para esferas superiores de valor. Pelo contrário, eles são a afirmação de que o conhecimento é um empreendimento humano dirigido por contingências sociais.

De maneira simétrica ao abandono do foco sobre as relações entre formas de conhecimento inferiores e superiores, não se entende mais que o indivíduo necessita conectar sua existência particular com valores transcendentes. Assim, o sentido da vida vem da própria vida e não de outra instância independente de 
valor com a qual se faz necessária uma conexão especial. $O$ indivíduo não necessita estabelecer uma relação de sua finitude com uma suposta existência após a morte, com um progresso histórico da humanidade ou com virtudes supremas transcendentes. Isto é, a vida de cada um de nós vale por ela mesma, sem que tenhamos que buscar a origem de seu valor em outras dimensões superiores, que forneceriam uma moldura mais ampla de significados. A instância particular possui sentido imanente e não o retira de algo superior. Sendo assim, ela não necessita de nenhum movimento de superação em direção a uma melhor compreensão ou a um patamar mais elevado de liberdade (LIPOVETSKY, 1987).

Não há mais necessidade de emancipação na medida em que o homem não entende sua existência particular como algo que carece de um sentido próprio e que solicitaria esse sentido de outra esfera. Não se percebe mais a necessidade de envolver a individualidade com um conjunto de valores que a orientem $e$ lhe forneçam princípios ou direção. O indivíduo vale por si mesmo.

O diagnóstico de Lyotard (1979), expandido além de sua pretensão epistemológica inicial, implica em uma espécie de limitação da esfera dos valores ao que é dado: um saber vale porque existe, uma vida possui valor porque é uma vida, o indivíduo não busca fora de si um complemento existencial. A nossa condição cultural envolveria, portanto, a eliminação de qualquer modalidade de transcendência e de fontes externas de valor.

Ao contrário do que poderia parecer à primeira vista, isso não significa uma acomodação a uma condição inferior. A questão é que simplesmente não se sente mais a necessidade por conexão com valores superiores, porque já estamos dotados de tais valores. Obviamente, dado que não se percebe uma carência ou uma falta de sentido, não se requer um complemento - de conhecimento, de liberdade, de progresso emancipatório. A questão importante, nesse caso, é a falta de sensação de carência por valores superiores.

Essa atitude não é de acomodação ou covardia diante de uma situação desafiadora, como se nos faltassem forças para um empreendimento de 
engrandecimento. O heroísmo deixou de ser buscado porque não se percebe mais que estejamos em um contexto que requeira engrandecimento, porque o valor já está dado de maneira imanente. Assim, não é mais necessário ampliar o círculo para além da nossa condição atual de conhecimento e de liberdade, porque não há um âmbito externo mais valioso. Certamente que não estamos de posse efetiva de todo conhecimento e de toda liberdade, mas estamos certamente de posse de tudo aquilo que necessitamos para obtê-los - sem que precisemos recorrer a outras instâncias independentes de valor (SILVEIRA, 2011). Não se busca conexão porque não se sente falta de um complemento, portanto não há um empreendimento heroico a ser realizado.

Embora não seja possível desenvolver aqui plenamente a ideia da imanência do valor, observo que ela está diretamente ligada ao aprofundamento da democracia nos regimes liberais contemporâneos. A atual situação cultural de perda da importância da transcendência é uma consequência da intensificação dos valores democráticos de igualdade e liberdade. É a valorização crescente da igualdade dos indivíduos que vem exercendo uma força planificadora nos sistemas hierárquicos herdados de modelos de vida aristocráticos e verticais (LIPOVETSKY, 1992; READINGS, 1997).

Alguns eventos contemporâneos são especialmente eloquentes a esse respeito. O movimento Occupy e o site WikiLeaks são expressões culturais da noção de que não se reconhece uma moralidade alternativa e exterior à do indivíduo. Nem o Estado nem qualquer outra esfera da atividade humana são reconhecidos como dotados de um conjunto de valores que teriam validade independente daqueles que os próprios indivíduos possuem. Assim, eles passam a ter sua autoridade sistematicamente criticada e corroída em função de una independência que é, cada vez mais, compreendida como tendo sido usurpada dos indivíduos (SILVEIRA, 2012). Esses valores podem ser entendidos como o desdobramento cultural contemporâneo das críticas feitas à religião e à cultura ocidental cristã por Feuerbach (1989) e Nietzsche (s.d.), respectivamente. 
O que é importante destacar, tendo em vista os objetivos desse artigo, é que a perda do valor de tudo que transcende a esfera individual é também a perda de valor daquilo que tornava a Filosofia uma atividade importante para o conhecimento e para a emancipação dos homens. O conhecimento não necessita mais ser justificado por meio de uma conexão a princípios superiores e o indivíduo não necessita de horizontes abrangentes para dar sentido a sua existência particular e tornar-se emancipado.

É como se a estrutura hierárquica dos dois modelos anteriores houvesse se fragmentado em instâncias isoladas e autossuficientes de valor. A Filosofia, que fornecia o núcleo de sustentação para um conjunto articulado de conhecimentos $e$ valores, perde a função centralizadora nesse contexto de dispersão generalizado. Não há mais um centro a partir do qual pudéssemos continuar a derivar a importância da atividade filosófica. Tudo indica que os filósofos perderam o núcleo em que se encontravam instalados naqueles dois modelos.

A cultura contemporânea liberou as instâncias particulares da necessidade de unidade orgânica, vale dizer da necessidade de hierarquia típica das formas de vida aristocráticas. A difusão e a absorção da democracia na vida cotidiana colocam os valores em um mesmo patamar e não requer qualquer forma de ordenamento já que, por definição, todas as particularidades são iguais. Dessa forma, percebemos como aquelas duas formas históricas de justificação da importância do trabalho filosófico perderam sua força e seu sentido em função de um ambiente cultural que tende a intensificar o modo de vida democrático.

\section{Milenarismo e rendição}

Em função desse panorama, parece evidente que as resposta para as perguntas sobre a pertinência da Filosofia no contexto do mundo contemporâneo tem de ser negativas. Não parece haver um lugar especial nem uma função garantida na cultura atual para nós, os filósofos. Se não há mais um centro que 
estruture um sistema de valores, não há como defender a centralidade da atividade filosófica para o conhecimento ou para a emancipação do homem.

Há algumas reações que permitem tornar mais perceptíveis a sensação de falta de pertinência da atividade filosófica com relação a essa nova situação cultural em que vivemos. Uma das reações, mais imediata e quase instintiva, é a tentativa de reafirmação dos valores clássicos - de maneira semelhante à forma como eles se apresentam em Aristóteles e Hegel. Essa perspectiva é grandemente difundida como uma espécie de consenso existente entre muitos acadêmicos - professores de Filosofia do ensino superior - embora não apareça como uma manifestação teórica explícita.

Ela afirma que o que está errado nesse quadro de falta de pertinência da Filosofia é a cultura contemporânea por ter se tornado fragmentária e valorizado a superficialidade. $\mathrm{O}$ isolamento das instâncias particulares de valor é um indício de decadência moral e cultural. A aceitação igualitária de tudo implica na impossibilidade de uma avaliação independente do que quer que seja, já que não há critérios superiores para isso. Enfim, se acusa o presente por haver se tornado indigno da Filosofia e por ter voltado suas costas à própria capacidade crítica que caracterizaria nossa atividade.

Essa perspectiva certamente permite que muitos filósofos adotem uma postura de indignação contra o mundo atual e de reafirmação do componente crítico da atividade filosófica. Entretanto, ela também amplia a imobilidade política e a falta de conexão da Filosofia com o restante da cultura. Dificilmente a Filosofia estará em condições de intervir em algum processo cultural se defende a ideia de que os valores predominantes estão essencialmente errados. A arrogância presente nesse tipo de postura é mais apropriada para seitas religiosas milenares, que anunciam o fim de um mundo corrompido para que um novo possa surgir, do que para a Filosofia.

Parece-me inaceitável que a Filosofia se reduza a uma espécie de seita milenar desse tipo. Entretanto, se seguirmos essa maneira de pensar, temo que a 
Filosofia perca gradativamente sua importância cultural, na mesma proporção em que a democracia se tornar efetiva como forma de vida no ocidente. Quem adota essa postura terá que admitir que a Filosofia sempre foi uma inimiga da democracia, pelo menos desde Platão (1996). Talvez a novidade resida no fato de que, hoje, essa contradição tenha se tornado insustentável e a Filosofia deve adotar uma posição defensiva e marginal. Mas isso significaria admitir também que a cultura contemporânea está gradualmente eliminando a atividade filosófica em função de seu espírito antidemocrático. O que, de certa forma, torna justa essa exclusão.

Embora se trate de uma questão política prática, sobre a qual nenhum conceito possui controle, não creio que essa maneira de entender a Filosofia conquiste o coração e a mente das novas gerações de filósofos. Isso na medida em que sua estratégia de sobrevivência é a de desqualificar os valores da cultura atual e de tentar manter aquelas duas velhas funções filosóficas em um novo contexto, que não requer mais esse tipo de atividade. Certamente, qualquer filósofo tem o direito de manifestar seu desgosto e seu inconformismo com a situação atual, mas colocar-se contra a maré democrática da cultura ocidental implica em demandar a elaboração de outro projeto de civilização.

Enfim, trata-se de uma maneira legítima de entender o problema, embora me pareça que ele conduza à arrogância e à amargura - duas características que não me parecem dever estar associadas à Filosofia. Além disso, ela possui uma tendência a gerar vociferações e condenações contra o suposto estado de decadência do mundo atual - no melhor estilo profético do Evangelho de João Batista - e nada mais. Observe que os defeitos dessa maneira de compreender o mundo atual e a atividade filosófica que estou indicando são morais e não conceituais. Espero que esses defeitos possam ser suficientemente eloquentes para afastar os filósofos do milenarismo.

Dentro de um quadro mais próximo de redefinição das funções do trabalho filosófico, há posturas que me parecem capazes de exercer alguma influência 
prática de maneira mais perceptível. Incluo nessa categoria as tentativas de dar à Filosofia uma feição semelhante a da ciência. Isso significa exigir que o trabalho filosófico deve imitar os procedimentos consagrados pela ciência: a definição prévia de um objeto de estudo, a adoção de uma metodologia e o estabelecimento dos limites de sua atividades. Essa demanda é feita, de tal forma que a Filosofia se torne responsável por um espaço particular dentro do escopo geral do conhecimento científico existente e desempenhe nele uma função específica.

Essa perspectiva propõe que a Filosofia imite uma ciência para adquirir um lugar ao sol e tornar-se respeitável. E respeitável significa "digna de uma consideração igual àquela que as ciências já possuem”. Essa postura me parece mais preocupada com o problema da ocupação dos filósofos e com a manutenção de seu status quo profissional do que com a questão da relevância da Filosofia para o mundo contemporâneo. Isto é, ela responde apenas ao problema de como manteremos nosso nível de empregabilidade, por meio de uma rendição às condições culturais existentes.

Isso se torna evidente quando observamos que sua preocupação é adequarse ao sistema de conhecimento vigente, apelando para uma forma de atividade que já possui respeitabilidade e reconhecimento do público e do Estado. Essa estratégia pode ampliar as condições institucionais de sobrevivência da Filosofia por meio de um comportamento mimético e perfeitamente adaptado ao ambiente. Entretanto, creio que ela consiste na própria negação da atividade filosófica.

Observe que essa perspectiva nada diz a respeito do problema de como a atividade filosófica deve se orientar no contexto da cultura contemporânea. $\mathrm{Na}$ verdade, ela recusa o próprio problema ao abandonar o âmbito em que ele se coloca. Ao limitar sua perspectiva a um determinado espaço epistemológico no interior da atividade científica, a Filosofia afirma que seu escopo de trabalho não é geral e sim particular. Isto é, que a definição de um objeto de estudo e de um método é sua regionalização epistemológica e a perda da perspectiva de entendimento global da cultura. 
Parece-me que essa proposta de adequação às condições de existência da atividade científica não responde ao problema que estamos formulando. Pelo contrário, ela é a recusa do próprio problema e responde a outro nível de preocupações: aquelas orientadas para a preservação do mercado de trabalho $e$ das condições de empregabilidade. Nesse caso, a Filosofia não somente aceita integralmente a dispersão e a fragmentação típicas da cultura atual como as assume como determinantes para seu trabalho. Diante da possibilidade crescente de perder o lugar privilegiado no contexto da cultura, essa perspectiva se refugia no particularismo - uma condição já disponível nesse ambiente - como estratégia de sobrevivência profissional e institucional. Podemos notar que não se trata propriamente de uma redefinição e sim de uma acomodação.

Observe que as duas reações à condição contemporânea que apresentei são extremas: uma quer fazer a totalidade da cultura retornar ao passado, negando-a por completo. A outra pretende tomar essa mesma situação cultural como um dado intransponível, de tal forma que tudo se reduz a achar um lugar para os filósofos, e não para a Filosofia, debaixo de um sol já bem estabelecido. Uma nega e a outra aceita integralmente as condições existentes no atual ambiente cultural.

\section{Pés no chão e cabeça ao vento}

Discordo de ambas as reações. Entendo que necessitamos de uma postura plástica e flexível. Os filósofos certamente precisam se ocupar da redefinição das funções de sua atividade, porém isso deve ocorrer a partir do quadro da cultura contemporânea. Sair dele é construir um discurso alienado e destituído de sentido para a porção não filosófica da humanidade - seguindo a rota do milenarismo. A indignação contra um estado de coisas é uma postura confortável que não conduz a nenhum resultado prático e apenas satisfaz uma necessidade subjetiva por superioridade - típica da minoridade. Não percebo nenhuma qualidade transformadora do mundo quando se sonha publicamente com as glórias perdidas 
do passado e se deseja a reversão dos processos históricos. Esta é uma postura que visa somente o conforto subjetivo.

Também acredito que a acomodação não é a atitude adequada diante da situação, como se tudo o que nos interessasse fossem postos de trabalho, bons salários no ensino superior e currículos que exibem produtividade. Nosso desafio como filósofos consiste em partir da situação contemporânea, mas não considerála como um horizonte intransponível. A cultura atual é um dado que não pode ser ignorado, porém ele deve ser considerado como um horizonte de possibilidades novas que demanda nossa atenção. Parece-me, inclusive, que essa relação adulta e tensa com a respectiva cultura sempre foi uma marca da atividade filosófica.

Acredito que devemos tomar pé diante da situação atual imbuídos do espírito de diálogo. O diálogo filosófico com a cultura contemporânea exige duas coisas. Em primeiro lugar, adotar o ponto de partida do conhecimento histórico da Filosofia que é, afinal, o que nos define e nos dá uma certa unidade de conhecimento e de ação. Sem a História da Filosofia não há um interlocutor filosófico e é desse último que o diálogo deve partir. De fato, é a história da nossa atividade que nos fornece um ponto de apoio comum, mesmo dentro de sua extrema variedade.

Em segundo lugar, precisamos reconhecer nas condições de vida atuais, novas necessidades que ainda carecem de interpretação e para as quais se requerem novas soluções. Ou seja, trata-se de considerar a tradição filosófica e a nossa situação cultural atual como elementos que potencializam a produção de novas compreensões do mundo e de nós mesmos e não como limites insuperáveis que devemos negar ou forças coercitivas às quais devemos nos acomodar. Requerse, então, ousadia para a transformação dessas condições iniciais em novas formulações filosóficas ainda inexistentes. Um diálogo só se mostra produtivo quando o que pode ser dito por um dos interlocutores - a Filosofia e a cultura contemporânea - tiver possibilidade de reverberar de maneira significativa para o 
outro. Interromper a comunicação é danoso para o diálogo porque impede que as duas partes se enriqueçam.

Adotar a postura de diálogo com a cultura de sua época é diferente de defender que o filósofo se torne um profissional parecido com os que já existem por exemplo, que ele se torne um filósofo clínico, um filósofo experimental ou um filósofo cientista, responsável por um aspecto particular do conhecimento entre tantos outros. Essas são respostas típicas de adaptação e de acomodação destituídas de coragem, de abertura para o desconhecido e do próprio espírito filosófico.

Estar disponível para esse diálogo também é diferente de afirmar que o filósofo deve se limitar a acender velas no santuário sagrado da História da Filosofia, como se sua função fosse a de um crente que venera algum outro filósofo, supostamente dotado de uma aura superior. O zelo com o passado tem colaborado da formação de muitos bons historiadores $e$ fortalecido o conhecimento da história da nossa atividade. Entretanto, isso não substitui a necessidade de dialogar com o presente de maneira a criar novas soluções para os problemas que são vividos hoje.

A ousadia implica em formular alternativas de diálogo com a cultura contemporânea que ainda não foram travados, de considerar os valores democráticos como interlocutores que se impuseram como capazes de plasmar um mundo que não existia - e que é o nosso, hoje. Não faz sentido negá-lo como se ele fosse destituído de importância nem hipostasiá-lo à condição de um limite intransponível ao qual devemos nos subjugar. Nesse tipo de diálogo, não existem limites intransponíveis, só existem condições iniciais. É essa constatação que deveria orientar uma relação filosófica com a cultura atual.

$\mathrm{Na}$ verdade, não estou defendendo nenhuma proposição nova para a Filosofia, pois se há algo que me parece ter sempre caracterizado o trabalho dos filósofos foi a capacidade de viver por sua conta e risco, sem perder de vista a relevância do seu trabalho para o restante da humanidade. Esse estilo de tomar 
posição com relação à atividade filosófica implica em afirmar uma maneira de viver diferente, a partir de um mundo que sempre nos é dado. Aos filósofos sempre coube a proposição de outras maneiras de viver, de outras maneiras de amar, de outras maneiras de respirar o oxigênio que a cultura nos oferece de graça.

\section{Referências}

ARISTÓTELES. Ética a Nicômacos. 4. ed. Tradução Mário da Gama Kury. Brasília: Editora da UnB, 2001.

Metafísica. Tradução de Valentín Yebra. Madrid: Gredos, 1990.

FEUERBACH, L. A essência da religião. Campinas: Papirus, 1989

HEGEL, G. W. F. Introdução à História da Filosofia. São Paulo: Hemus, 1983.

. Encyclopédie des sciences philosophiques. Tradução de Bernard Bourgeois. Paris: J. Vrin, 1988a.

. Fenomenologia do espírito. Tradução de Paulo Meneses com a colaboração de Karl-Heinz Efken. Petrópolis: Vozes, 1992.

KUHN, Th. A estrutura das revoluções científicas. Tradução de Beatriz Viana Boeira e Nelson Boeira. São Paulo: Perspectiva, 1989.

LYOTARD, J.-F. A condição pós-moderna. 7. ed. Tradução de Ricardo Corrêa Barbosa. Rio de Janeiro: José Olympio, 2002.

LIPOVETSKY, G. L'empire de l'ephémère: la mode et son destin dans les sociétés moderns. Paris: Gallimard, 1987.

Le crépuscule du devoir. Paris: Gallimard, 1992.

NIETZSCHE, F. Humano, demasiado humano. São Paulo: Escala, s.d.

PLATÃO. A República. Tradução de Maria Helena Pereira. Lisboa: Fundação Calouste Gulbenkian, 1996.

PRADO. A. Oráculos de maio. São Paulo: Siciliano, 2007.

REAGINGS, B. The university in ruins. Cambridge: Harvard University Press, 1996.

SILVA, A. F. O conceito de Liberdade (Freiheit) como fundamento da noção de Educação (Bildung) em Hegel. Revista Sul-Americana de Filosofia $e$ Educação. N. 17, nov/2011-abr/2012, p. 3-13.

SILVEIRA, R. A. T. A filosofia e a nova história. In: III Congresso Internacional Feuerbach. [Comunicação] agosto de 2011.

- O florescimento da subjetividade contemporânea. Associação Nacional de Pós-Graduação em Filosofia (ANPOF). Disponível em http://www.anpof.org.br/comunidade/system.php?_action=encontro trabalho Acessado em 8/07/2012. 